\title{
The social and political impact of the privatization of groundwater: conflict and cooperation around the aquifer of Saïss, Morocco
}

\author{
R. Fofack \\ University Paris Ouest Nanterre La Défense, France
}

\begin{abstract}
From the beginning of the 1980s, irrigated agriculture in the Saïss plain, located in the North-East of Morocco, has mostly been made through groundwater resources. The aquifer is at the centre of various stakes, one of the most important of which is related to the privatization of modes of access and use of water for irrigation. Indeed, the transition from irrigation through surface water to an irrigation based on groundwater has contributed to the appearance of new actors in the aquifer's area. This is even more accentuated as the transition to groundwater has modified rules for water access. From a community management point of view, they are now governed by a private and individualistic field: wells and tube-wells are personal, both regarding their process of construction and use. This rapid privatization generates conflicts for appropriation, use and control of resources between actors around such heterogeneous aquifer. Traditional, emergent and invisible actors, they all meet or avoid each other, either in a conflictual way or by developing cooperation. Who are these actors? What are their strategies and how do they deploy them in order to handle the access, use and control of groundwater? A case study led in three villages in the Saïss plain highlights the "sharing logics" of groundwater resources, in a context which is characterized by a growing scarcity of available resources. Our object is, first to analyse axes of conflict and cooperation and, secondly to show that these logics are multi-scale, multi-subject, and evolving.

Keywords: privatization, groundwater, irrigated agriculture, conflict, cooperation, Saïss, Morocco.
\end{abstract}




\section{Introduction}

The history of irrigation development in Morocco from the early $20^{\text {th }}$ century has focused on the political ambition to manage and control overall available surface water resources. That led governments, under the French Protectorate and after Independence, to emphasize the shifting of a legal, institutional framework and important infrastructures around the large and medium scale Hydraulics (Bouderbala [1]). Excluded from these major investments, we observe with the beginning of the 1980s the development of an irrigation based on groundwater resources. This form of irrigation is encouraged by the rapid growth of wells, tube wells and innovations in technics of pumping aquifer. While State controlled or delegated exploitation of surface water resources (to small-scale irrigation communities), the exploitation of groundwater resources in irrigation has been mainly conducted by farmers, which are private actors. As in India (Shah [2]), or Spain (Lopez-Gunn and Llamas [3]), the absence or weakness of Moroccan state regulation over groundwater access has allowed the development of an informal, mostly private and individual access to these resources (Bekkar et al. [4]). At the scale of his farm, each farmer has "his own water" through well or tube well built by his own means. With irrigated agriculture by surface water, access to the resource was collectively managed. On the contrary, rules in irrigated agriculture with groundwater are governed by private and individualistic logic at all the levels of water exploitation (digging wells, buying moto pumps, using and maintaining). This article considers the privatization of groundwater both as the process and the result of an internalization of costs, risks and advantages around access to this groundwater resource at the scale of a farm.

This privatization of groundwater generates new forms of conflicts and cooperation between public and private actors for the appropriation, use and control over the aquifer. Therefore, the situations of conflict and cooperation focus on both, different or shared visions of the aquifer uses and contrasted or shared interests linked to these uses. This paper aims to analyse actors' strategies deployed for controlling over and access to groundwater resources. How do they set their actions and inter-relations between them? What could be the modalities of sharing groundwater, in a context of progressive scarcity of available resources? What forms do conflicts over groundwater take? The sociological analysis of environmental conflicts involves a study of situations and objects of conflicts. That means to identify the stakes and the parameters of these stakes (knowledge, norms, and actors). To analyse situations of conflict and cooperation around groundwater in the Saïss, the paper highlights the concept of framing developed by Mormont [5].

In the study of interactions, the concept of framing examines how an actor consider the specific situation he is getting involved in and shape his space of communication with others (Goffman [6]). On the other hand, such operation must be considered on two scales: the framing is first an actor but also a result in different contexts. By this way, the framing of an issue concerns the procedures by which are constructed valuable elements in defining this issue, its stakes or interests and relevant actors (Mormont [5]). Therefore, a conflict concerns not 
only uses and actors, but also derives from a lack of consent during the qualification of what it is the actors value the most and how this value should be assessed. The socio-political interactions in terms of cooperation in Morocco refers to the arrangements between private actors trying to adapt to different social, political and environmental transformations (Bekkar et al. [4]; Boudjellal et al. [7]). Access to and exploitation of groundwater resources have led to the emergence of new issues in irrigation scale, carried by actors who shift new forms of individual or collective initiatives. Cooperation means the implementation of agreements, negotiations and arrangements and therefore highlights the sharing of common values. Its aim is finally to specify organisational and economics modalities of interactions between actors (Becker [8]).

The study has been conducted in the Saïss plain, an aquifer located in NorthEast Morocco (see figure 1). Irrigated agriculture in this region is mostly made through groundwater resources of the aquifer.

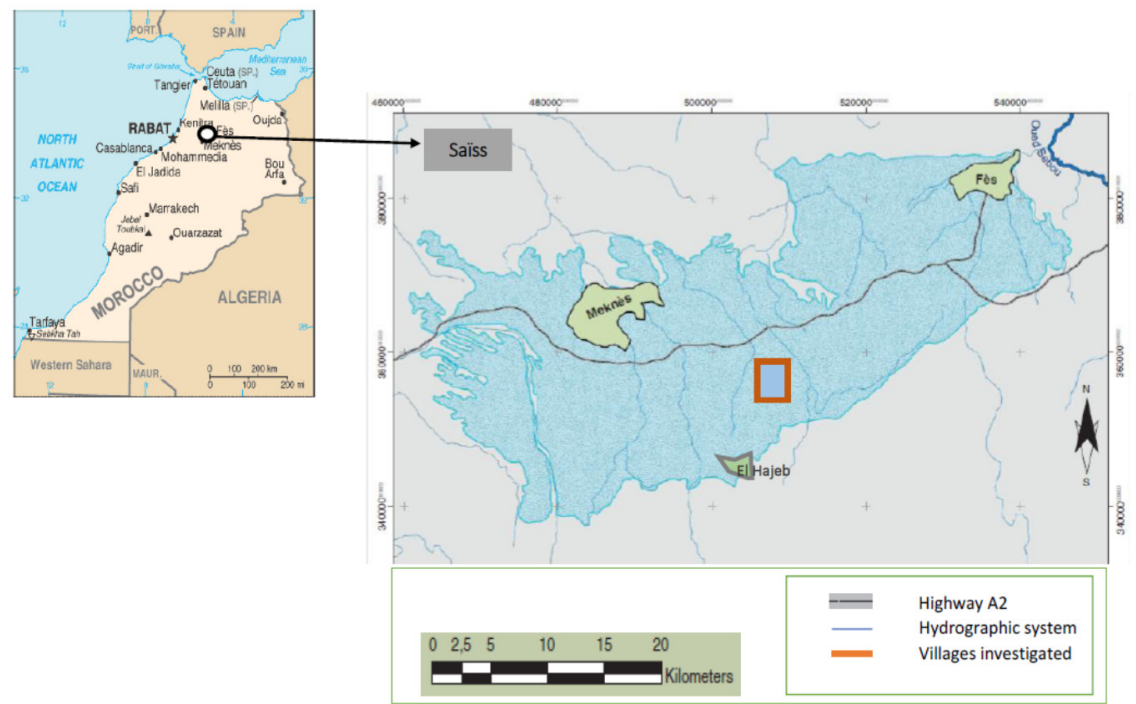

Figure 1: Localisation of the Saïss plain (map base: Hydraulic basin agency, 2011).

Field study includes investigations and interviews led in two different stages with two categories of actors. Firstly, we have main institutional actors involved in the access to, use and exploitation of the aquifer: the hydraulic basin agency, the regional and departmental directions of ministry of agriculture, and the two regional chambers of agriculture. Secondly on the side of private actors, the study concerns many investigations in three villages in the Saïss. In all, it has been led on 94 farms, and on 182 wells and tube wells.

Referring to the framing, conflict and cooperation should be considered as two extremes of the same gradient. On the one hand, this progressive gradient moves from tensions in raising the aquifer as an important stake in political agenda, to 
conflicts between institutional actors involved in the groundwater resources management. On the other hand, the gradient move to cooperation by including various forms of arrangements, negotiations and conciliations between private actors around access to, and use of these resources. In order to present a complete vision of these two modalities of conflict and cooperation, the paper first starts by an analysis of areas and arenas where conflict and cooperation operate. The second part examines key issues that appear with the introduction of the preservation of groundwater resources in Moroccan policies. The paper concludes by arguing that in both processes of conflict and cooperation, environmental issue is not a structuring element in the strategies of actors. These processes highlight the nonintegration of environmental stakes in a context over governed by a privatization of groundwater resources.

\section{Groundwater arenas in the Saïss plain: actors and dynamics}

This section presents institutional and private arenas by examining specific questions: how are they built, who are the actors involved, what interactions and forms of participation arenas define, induce or allow? The section also shows that arenas are not independent, that they meet and could communicate with each other. Two arenas are presented below: the Hydraulic agency basin and the farm.

\subsection{Hydraulic Agency basin of Sebou: space of institutional cooperation and conflicts over groundwater resources}

In 1995, Moroccan government adopted the water law (law 10-95) which codifies international principles of the integrated water resource management (IWRM) in the country. The law specifically delegates the management of water resources at the scale of watersheds to the Hydraulic basin agencies. In the Saïss, the Hydraulic basin agency of Sebou (basin agency) was created in 2005. Its aim is to lead and manage the regional politic for protection and conservation of surface and groundwater resources. The basin agency was created as a specific actor, but appears as an area of consultation and negotiation between itself and other relevant actors around groundwater resources access, use and exploitation. The composition of its executive board particularly emphasizes that status of institutional arena. The executive board consists of: 30 per cent of state representations, of which regional and provincial delegations of the ministry of agriculture have a strategic role; and about 40 per cent of both user representatives (chambers of agriculture, etc.) and local collectivities.

Indeed, this arena is the main space of interactions between three main institutional actors: basin agency for the aquifer resources safeguard, delegations of ministry of agriculture in charge of the development of an intensive irrigated agriculture, chambers of agriculture which are a socio-professional Corporation for the defence of farmers' interests. Between these three actors, the nature of interactions differ, depending also on the global and local influence of each one. The negotiations and process of decision-making reveal some modes of 
cooperation and interactions over conflicts between them. This appears firstly about the implementation of the regulation on aquifer drilling and pumping (law 10-95) and secondly about the creation of the Framework Convention relative to groundwater resources conservation in the Saïss (also called aquifer-contract).

\subsubsection{From coalition for the implementation of a regulation on aquifer drilling}

It is specified in the law 10-95 that wells and tube wells must have authorizations before drilling, or must be regularized after it. In 2009, a decree provides conditions and procedures for the mechanisms of authorizations and regularisations. One of the first challenges the new basin agency had to face, was the implementation of these rules. But the basin agency is strongly limited by an inadequacy of its missions to financial and human resources it is allowed. Indeed, it manages 375.000 hectares of irrigable areas over fifteen provinces with about 70 civil servants, engineers, administrative and technical agents. In comparison, the departmental delegation of the ministry of agriculture located at El Hajeb in the Saïss, employs about 40 agents at the smaller scale of one province. Dealing with weak resources, the effective application and, more importantly, the control of the respect of authorizations and regularisations rules appears technically an elusive goal in the groundwater irrigated zones of the basin. However, to reach its goal, the basin agency built a coalition with regional delegations of the ministry of agriculture which implement in the Saïss an offensive policy to increase irrigated areas through a large program of subsidies on drip irrigation for farmers. The coalition between the two actors consisted in including in the procedure of subsidies allowance, an obligation to provide authorizations or regularisations of wells or tube wells. Subsidies rates strongly encourage farmers to respect rules of authorizations and regularisations. Indeed, from $30-40 \%$ in 2002 the rates raised to $80-100 \%$ from 2010 (Benouniche et al. [9]). On the side of the ministry of agriculture, the gain is notable: the coalition on drip irrigation subsidies participates to reinforce coherence between sectorial policies (water and agriculture) on a global national strategy of water resources savings initiated with the IWRM.

\subsubsection{To conflicts over regulation of drilling and creation of the aquifer-contract}

The Framework Convention relative to groundwater resources conservation in the Saïss ("aquifer-contract") is a project initiated by the basin agency, to build a common vision and action, with institutional and private actors, of the access to, use and exploitation of groundwater resources. Since the project started, it has crystallised a lot of tensions and conflicts between the basin agency and the chambers of agriculture. Chambers of agriculture participate, closely with the delegations of ministry of agriculture, to the development of farmers' capacities in accordance with the national agricultural policy of the Green Moroccan Plan. Chambers are composed of elected representatives of farmers, who consider the arrival of the agency basin, its rules and its restrictions as major obstacles to farmers' initiatives and survival. 
Regarding authorizations and regularizations, chambers of agriculture have clearly contested the legitimacy of these rules and denounced inequalities in their application between large-scale and small farms. According to them, it is unfair to forbid drilling for irrigation to farmers who depend on it. In fact, farmers continue their illegal drilling. The project of aquifer-contract has reinforced conflicts between them because the project consider the creation of aquifer safeguard zones where pumping are forbidden, the limitation of the number of authorizations provided to small-scale farms $(<5$ hectares), the installation of water meters on wells and tube wells and the institution of water price for groundwater. Because of their smaller influence on this arena, their opposition has a double impact in the strategy of the basin agency. On the one hand, the chambers of agriculture are not included in the process of decision in the arena relative to these aspects of the project, and the basin agency has chosen to deal directly with large-scale farmers.

In short, the basin agency is one main arena where institutional forms of cooperation and conflicts over groundwater resources are set up. At the scale of private actors, modes of cooperation between farmers mainly appear at the scale of the farm.

\subsection{The farm, a relevant space of cooperation between private actors}

In the forms of interactions between farmers, the paper focuses on the cooperation for two main reasons. First because in the Saïss, individual access to, and use of groundwater is an informal rule (Ostrom [10]), which reduces many opportunities of conflicts we can observe in a context of common resources. Secondly, as a consequence of the first reason, circumstances of cooperation between farmers are not easily visible or evident. Indeed, the forms of framing are built in a case-tocase approach. They happening in a face-to-face relationship where the farm is the privileged arena of negotiation and arrangements. This section is about some prominent cases of cooperation between farmers in three Saïss villages. It also analyses the content of this cooperation, its organisation and economic modalities (Becker [8]).

\subsubsection{Three prominent cases of cooperation in the Saïss farms}

This study investigated 182 wells and tube wells in 94 farms in the Saïss. In order to have a quantitative dimension of privatization of groundwater access in this zone, only $6 \%$ of wells and tube wells investigated are collective. Three main cases and logics of collectivisation of groundwater access and use prevailed.

- The first case concerns a well dragged in the middle of the 1980 s on a 2 hectares farm inherited by four brothers. This is a typical familial well. The exploitation of the farm since the brothers shared it is individual, while they used a unique well to pump water for irrigation and domestic water. Costs for maintenance and functioning of the well were then shared. In 2008, the form of the share changed. Each brother started to install his own moto pump in the well (electric pump and gasoline moto pumps). Then we have the physical structure of the well shared, each partner provides his own equipment for pumping in the well. 
- In the second case of collective access to, and use of groundwater we have a business relation among the (tube) well. An owner has a land which is not exploited because of a lack of irrigation water. He gets an association with another farmer or funder. The association links their resources (land and money, land and groundwater resource) and involves an equal share of coats and benefits, in each other's investment.

- The third case or type of cooperation is relative to a reciprocal countergift dynamic. In this type, we have mainly short-time arrangements between two farmers. Indeed, a farmer can help another when the well of the second got dry during the irrigation campaign or when its equipment for water pumping (motor or pump) collapsed. The first farmer offers groundwater resource to the second, and could gain a social, symbolic retribution, present or future.

\subsubsection{The content and meanings of cooperation}

To explore cooperation among groundwater resource between farmers, it is important to answer this question: what is shared and what stays individual? This question helps to distinguish the (tube) well as the physical point giving access to the aquifer from the equipment (motors and pumps) pumping water to the surface. (Tube) well and pumping equipment are two different elements influencing the status and the content of the cooperation. Wells or tube wells are partially collective if farmers share only the physical access to groundwater resource. They are completely collective if the arrangements include both elements. In the first case, the mid-form collectivisation shows the farmers will to maintain a relative independence in irrigation planning and to reduce source of conflicts over groundwater resource. In the second case, that is total collectivisation, the relation is more consensual because the association mutualises risks regarding not only groundwater resource accessibility, but also risks on the global farm productions. But this last case of could also means a forced or obliged collectivisation. This appears in particular with family wells. Partners stay together because they do not have financial means to leave the cooperation.

In definitive, the paper in this first part identified two main public and private groundwater arenas in the Saïss: the basin agency and the farm. In each arena, it analysed how they are built, their modalities of participation and modes of functioning. The concept of framing involves an identification of arenas, but necessarily includes an analysis of the stakes that underpin actions within these arenas. The second part below deals with these stakes of framing.

\section{Analysing issues within groundwater arenas in the Saïss}

There are no arenas without issues (Mormont [5]). The following analysis addresses one question specifically: what are the issues raised by the building of frames of action? Issues construct and structure strategies within but also outside the arena, in the interactions with others arenas. In the Saïss, public and private arenas actually follow some common stakes, but in definitive these stakes do not deal with environmental issues. 


\subsection{Convergence of issues in the public and private sectors}

Convergence of issues in public and private arenas is visible through 1) the focus on groundwater resources use or exploitation, 2) the need for actors to maintain their prerogatives around these resources.

\subsubsection{Main issue 1: groundwater resources exploitation}

As in many countries, the rapid development of wells, tube wells and drillings in Morocco enabled the development of an intensive agriculture (Lopez-Gunn and Llamas [3]), which is supported by ambitious agricultural policies (the Green Moroccan Plan adopted in 2008). This agriculture contributes to about $15-20 \%$ of the national economy. Due to its aquifer system, the Saïss region produces $50 \%$ of national market productions on the onion subsector (Lejars and Courrilleau [11]). Then, the extension of irrigated agriculture in the region based on groundwater exploitation is a priority for the agricultural sector in particular, and the national economy in general. The basin agency has primarily been created in order to organize the distribution and control of groundwater resources by: "soft planning" (water law 10-95) groundwater uses and management, by codifying new rules of access to, and use for groundwater resources according to aquifer tables and national and regional development priorities. In clear, trade-offs must be made between different users and uses of groundwater resources, which is the role of basin agencies.

The project of a Framework Convention relative to groundwater resources conservation in the Saïss (aquifer-contract) also supplies a favourable environment for agricultural sector. This aquifer-contract addresses the implementation of water-demands strategy (projects and public investments to increase offer of water resources). Actually, agricultural sector uses 160 million of $\mathrm{m}^{3}$ per year of groundwater resources of the aquifer. To reduce this pressure on the aquifer for 2030-2040 (to 47 million of $\mathrm{m}^{3}$ per year), the aquifer-contract plans to substitute groundwater resources by subsurface water resources. This might be possible through its large plan of development of offer on water resources, including the construction of four large dams and a mechanism of artificial recharge of the aquifer.

\subsubsection{Main issue 2: maintain or built a legitimacy of intervention}

The need of a trade-off on groundwater resources has been a source of conflict between historical actors present in the Saïss (delegations of the ministry of agriculture, chambers of agriculture, and farmers in particular) and the recent basin agency. One of the stakes that appeared with the creation of the basin agency was the new repartition of competencies between actors. The redistribution lead to struggle between these actors for maintaining or building their legitimacy about groundwater. As analysed above, the conflict between chambers of agriculture and basin agency was about this legitimacy. This conflict extends beyond institutional arena to the farm. The processes of groundwater access by farmers are mainly individual and they also may be collective. But whatever the individual of collective mode of access, the high economic cost and social value of this access, as a means of emancipation and source of dignity (Quarouch et al. [12]) contribute 
to reinforce the informal privatization. On the one hand, farmers consider groundwater in (tube) wells as their own and basin agency has no legitimacy of intervention. Therefore, they reject the legislation on authorizations and regularisations. On the other hand, basin agency blames farmers' irrigation practices as waste water practices. And that justifies an emergency of pumping regulation. Finally, the strategy of subsidies on drip irrigation system represented a canal of communication between both types of actors.

\subsection{Exclusion of the environmental problematic in actors 'strategies}

As this paper addressed, there are some examples of framing which result on conflicts and some others on cooperation. However, the link between conflict and cooperation is the convergence of issues on both levels of framing. The importance to show this link through a tension between two modalities of groundwater privatization is the following: whatever the type of relation we are focusing on (conflict or cooperation), the environmental issue is not at the centre of both public and private actors and strategies. The conservation of the aquifer is not integrated as a focal point. In fact, when groundwater conservation and protection are present, they are addressed besides irrigated agriculture sustainability. The sustainability of groundwater resources is a benefit for agriculture. Table 1 below summarizes all the issues around the Saïss aquifer, and replace the in its role of developing agricultural sector.

Table 1: Overview of issues of framing in public and private arenas.

\section{Public arena}

\section{Private arena}

\section{a. Groundwater resource exploitation}

-Concerted implementation of rules of $\quad$ Family cooperation, business or authorizations and regularizations.

-Trade-offs between groundwater uses and actors. capitalistic cooperation.

\section{b. Reciprocal counter-gift dynamic}

Reducing pressure on aquifer tables by substituting groundwater to sub water resources.

Reducing pressure on aquifer tables by adopting drip irrigation through government subsidies.

-Controlling access on aquifer. -Impose new rules of drilling.

-Mastering the processes of groundwater access.

- Adapting this process to the relevant opportunities (subsidies).

d. Sustainability of groundwater resources

-Supporting the extension of agricultural -Sustaining irrigated agriculture. economy. -Allowing farmers' emancipation.

-Avoid a collapse for a durable use of resources. 
The fourth issue mentioned as "sustainability of groundwater resources" in table 1 details how groundwater resources protection is considered in arenas. In these arenas, the protection or the conservation of aquifer should serve to support the development of irrigated agriculture nowadays and in the future. Table 1 also shows how private and public arenas cross on many issues. These arenas are not closed. Actors communicate with and meet each other at different stages of the process of groundwater access and use.

\section{Conclusion}

This study concerns actors 'strategies deployed for controlling access to and use on groundwater resources. The analysis treated a problematic relative to diverse forms conflicts over groundwater and modalities of cooperation between actors in a context of progressive scarcity of available resources. By focusing on the notion of framing it has been possible to highlight not only arenas where actors set their actions or strategies, but also issues supporting all these strategies. The paper concludes by the fact that environmental issue is not a structuring issue in both public and private actors. The contradiction between political discourses relative to groundwater resources conservation and the effective strategies is also due to a constant tension. A tension between economic development objectives of the country and international pressures to observe an integrated water management resources in its policies (Del Vecchio [13]). At all, the two modalities of conflict and cooperation dynamics are an extension of this tension. On the one hand power and influence of agricultural sector, and on the other hand the poor means of the basin agency, guardian of the aquifer which does not control access and exploitation overall the aquifer. Besides, the relation of dependence of agriculture to groundwater resources since the beginning of 1980s, explains the reasons which the "management" of the Saïss aquifer has been introduced in the political agenda. The main issue was not an environmental need, but the emergency of a coordination between users and uses upon the common aquifer. The coordination then appeared as the condition to a durable use of the aquifer. Finally, the understanding of the governance of the Saïss aquifer must be taken into the prism of these tensions and political realities.

\section{Acknowledgements}

This study has been conducted with the support of the ANR project "Groundwater Arena" (CEP S/11-09). I specially thank Jean-Paul Billaud, my PhD thesis supervisor for his advice and orientations that helped me to enhance this paper. My gratitude also goes to Thierry Donnadier (NSS review) for revisions he proposed to improve the text form. I am obviously, the only one accountable for the views and analyses expressed in this paper. 


\section{References}

[1] Bouberbala N. 1999. L'aménagement des grands périmètres irrigués: l'expérience marocaine. In: Jouve A.-M. (ed.), Bouderbala N. (ed.), Politiques foncières et aménagement des structures agricoles dans les pays méditerranéens: à la mémoire de Pierre Coulomb, pp. 171-184.

[2] Shah T. 2009. Taming the Anarchy: Groundwater Governance in South Asia. Washington DC: Resources for the future press.

[3] Lopez-Gunn E. and Llamas M.R. 2008. Re-thinking water scarcity: Can science and technology solve the global water crisis? Natural Resources Forum 32: pp. 228-38.

[4] Bekkar Y., Kuper M., Errahj M., Faysse N., Gafsi M. 2009. On the difficulty of managing an invisible resource: Farmers' strategies and perceptions of groundwater use, field evidence from Morocco, Irrigation and Drainage 58: S252-S263.

[5] Mormont M., 2006. Conflit et territorialisation, Géographie Économie Société 3 (8): pp. 299-318.

[6] Goffman E., 1974. Frame Analysis: An Essay on the Organization of Experience, New York, Harper.

[7] Boudjellal A.A., Bekkar Y., Kuper M., Errahj M., Hammani A., Hartani T. 2011. Analysis of local arrangements to access groundwater in the Mitidja (Algeria) and Tadla (Morocco) irrigation schemes. Cahiers Agricultures 20 (1): pp. 85-91.

[8] Becker H. S. 1982. Art Worlds, Berkeley and Los Angeles: University of California Press.

[9] Benouniche M., Kuper M., Poncet J., Hartani T., Hammani A. 2011. When small-scale farms adopt drip irrigation: Local initiatives and state programs in the Gharb (Morocco), Cahiers Agricultures 20: pp. 40-47.

[10] Ostrom E. 1990. Governing the Commons: The Evolution of Institutions for Collective Action. Cambridge University Press.

[11] Lejars C. and Courrilleau S. 2015. Impact of agricultural groundwater use development on an irrigated sub-sector: The case of the onion in Saiis (Morocco), Cahiers Agricultures 24 (1): pp. 1-10.

[12] Quarouch H., Kuper M., Abdellaoui E.H, Bouarfa S. 2014. Subterranean waters, a source of dignity as well as a social resource: The case of farmers on the Saïss plain of Morocco. Cahiers Agricultures 23 (3): pp. 158-165.

[13] Del Vecchio K. 2013. La mise en place d'un contrat de nappe dans le Saïs: analyse du changement de politique publique. In Hartani T., Kuper M., Belhamra M., Proceedings of international seminar on groundwater governance in Maghreb, pp. 93-95. 